\title{
An assessment of danger during spring floods and ice jams in the north of European Russia
}

\author{
N. L. Frolova, S. A. Agafonova, I. N. Krylenko, and A. S. Zavadsky \\ Lomonosov Moscow State University, Moscow, 119991, Russia \\ Correspondence to: N. L. Frolova (frolova_nl@mail.ru) \\ Received: 15 April 2015 - Accepted: 15 April 2015 - Published: 11 June 2015
}

\begin{abstract}
Heavy ice jams during spring floods are common on rivers in the northern European Russia. Climate changes of the last decades have caused significant changes in the ice regime of rivers. Continuous freezing periods, followed by sludge ice jams and late freezing at high water levels, occur with increasing frequency. Winter break-ups have become more frequent. The most recent catastrophic flood in the area under study took place in the spring of 2013. The probability of floods and ice jamming is evaluated; the duration and depth of inundation at various water levels are calculated with an assessment of the accompanying economic losses in the Northern Russia.
\end{abstract}

\section{Introduction}

The use of water resources is inevitably accompanied by an increase in the risk of exposure of the public safety, as well as the social and industrial facilities on riverbanks due to the effect of hydrological processes. The details of the analysis of hazardous hydrological phenomena and consequently the assessment of the natural risk depend on the spatial scale of the study (Frolova et al., 2004). This scale determines the structure of the source information, the methods of its processing, and the choice of appropriate indicators and the features of the phenomena to be displayed on the map. A method for solving this problem is described here as applied to some developed reaches of the Northern Dvina River from the confluence of the Sukhona and Yug rivers, at Velikiy Ustyug one of the oldest cities in the northern Russia to Kotlas City at the inflow of the Vychegda River (Fig. 1). It stretches from the south to the north almost along meridian, so powerful ice jams form during spring floods on the Sukhona, Yug, and Northern Dvina practically every year. The control of accompanying inundations has been an ongoing issue there for more than a century. The major ice jams are often $10-20 \mathrm{~km}$ in length, and their lifetimes range from several hours to 3-5 days. Nine catastrophic floods, which caused enormous economic damage, were recorded within this reach from 1877 to 2013. The assessment of the possible flood risk required thorough analysis of historical, geograph- ical, hydrometeorological, social, and economic information; field studies; the development of methods for calculation and prediction of hazardous ice phenomena in view of possible climate change; simulation of manifestations of dangerous hydrological processes based on different scenarios; the evaluation of the probable damage caused by the adverse impact of water, including the analysis of the efficiency of measures against ice and sludge ice jams; and eventually, the development of recommendations regarding protective measures.

\section{Study area}

The Northern Dvina is a typical river of the northern European Russia (Vuglinsky, 2002).The reach of the Northern Dvina under study, about $90 \mathrm{~km}$ in length, is located from the confluence of the Sukhona and Yug rivers (Velikiy Ustyug) to the inflow of the Vychegda R. (Kotlas). Five water stage gauges record water levels within this reach, and two of them (upstream) record water discharges. The rivers are mostly snow-fed; they show high spring floods and low winter lowwater periods. No statistically significant changes were identified in recent years in the rate of stream flow and the character of its seasonal distribution.

The probability of a dangerous water rise during high spring floods due to snowmelt inflow and the backwater effects of ice jams in the river reach as of 1946-2013 is about $30-35 \%$ (Fig. 2). 


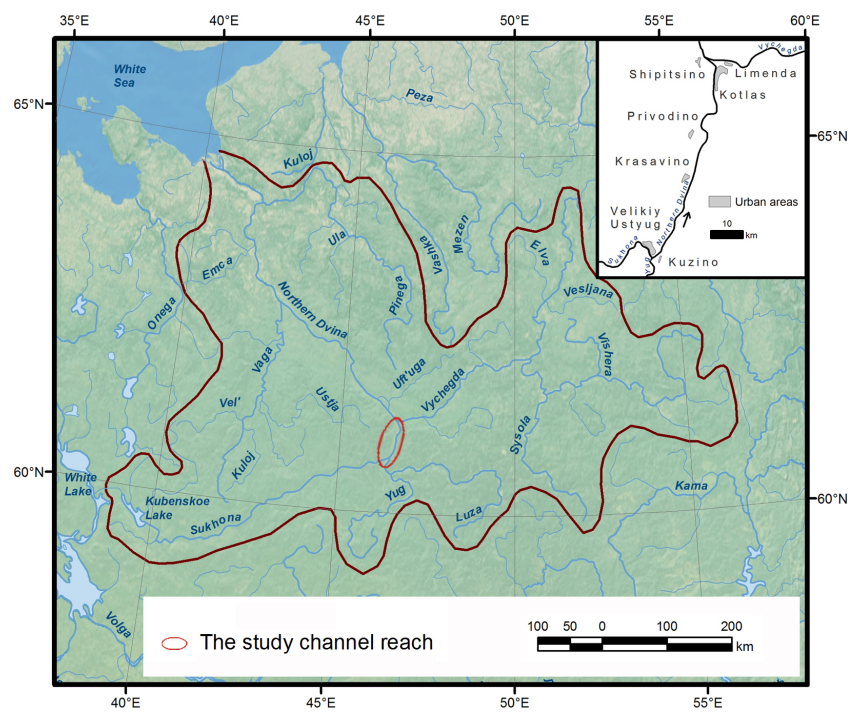

Figure 1. The study area.

An attempt was made to identify changes in river ice regime on the basis of hydrometeorological data covering two distinct periods: 1961-1990 (baseline) and 1991-2013 (present). The results of this study allowed trends to be identified and conclusions on possible qualitative and quantitative changes in river ice hydrological characteristics to be made. However, the quantitative change of various river ice regime characteristics is not so obvious and depends on the ice regime phase. The results of statistical analysis of the dates of floating ice occurrence and freezing up show, for example, that the shift in mean freeze-up dates in 1991-2013 increased by seven days as compared to the period of 19611990 (Fig. 3). In many cases, the change in freeze-up duration occurs due to later freezing (Fig. 3). Upward trend in dates and duration of freeze up period is statistically significant. Trend's significance has been evaluated using Spearman's rank correlation coefficient.

Such changes are associated not only with increase of air temperature in autumn prior to freezing, but also with the specifics of rivers regime. When the temperature regime for the study region becomes milder, the low water flows at the beginning of autumn are observed more frequently, which leads to early freeze-up dates. Air temperature fluctuations during autumn may cause a return of positive temperatures in November and result in floods due to snow melting and rain. High water levels during this period stimulate later freeze-up, increase of autumn ice and sludge drifts duration and formation of ice jams. Later freeze-up shortens the period of exploitation of ice crossing - an important feature of the north of Russia.

The milder winter conditions due to climate change result in the decreasing sum of negative air temperatures, increasing volume of solid precipitation and increasing number of positive air temperatures events that cause thawing spells (for

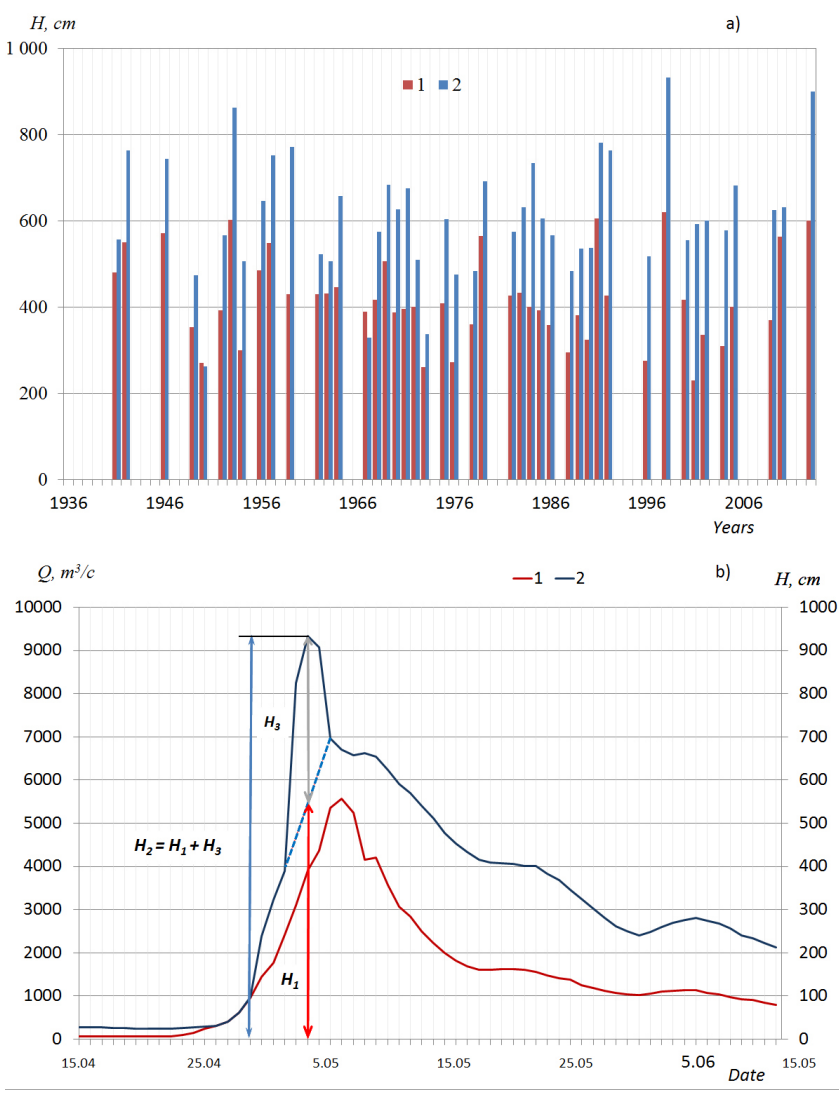

Figure 2. Changes in the flow component $H_{1}(1)$ and maximum water levels $H_{2}(2)$ in years with ice jams ( $H_{3}$ is the ice jam component of water level) (a) and scheme of its identification in the case of the flood in 1998 (changes in water level (1) and water discharge (2) for Sukhona River near Velikiy Ustyug) (b).

many weather stations, the analysis of meteorological time series points out to the existence of statistically meaningful trends in these characteristics). The change in the maximum ice thickness during 1991-2013 compared to 19611990 is found to exceed $10 \mathrm{~cm}$, which is statistically significant. The air temperature in winter often becomes positive and changes in sum of negative temperatures and ice thickness are more evident. On one hand, thawing spells lead to winter break-ups that are accompanied by catastrophic ice jams due to increased discharge and associated volume of sludge along river channels. Ice jams developed during such periods may cause subsequent spring ice jams. On the other hand, longer thaws result in thin ice cover and decreasing snow supply. High water levels during ice jam periods and large volumes of sludge form favorable conditions for hazardous ice jams during break-ups. Another example of adverse river ice regime changes is the reduction of ice crossings' exploitation periods due to winter break-ups and reduced thickness and strength of the ice.

The changes of the river ice regime during spring are also ambiguous. Spring processes begin with the date of 


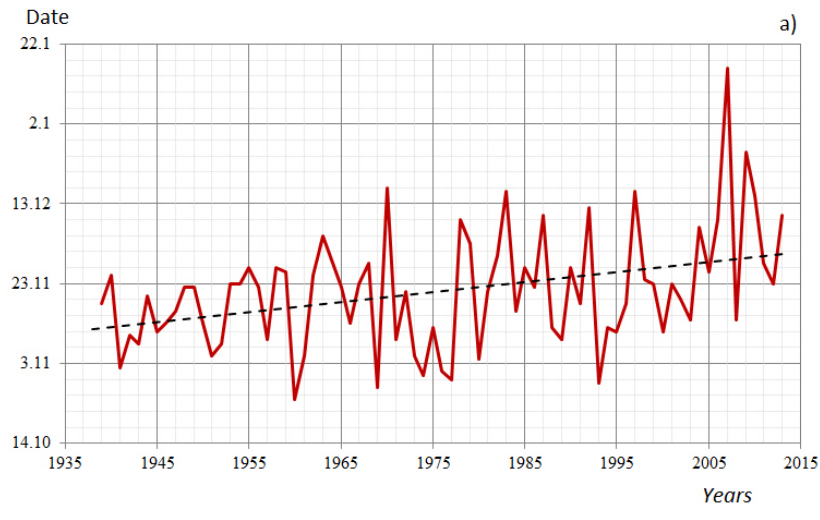

$T$, days

b)

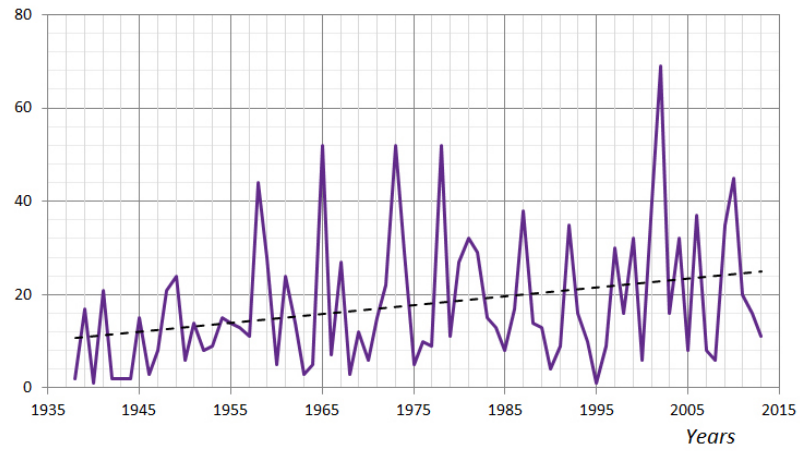

$h_{\max }, \mathrm{cm}$ c)

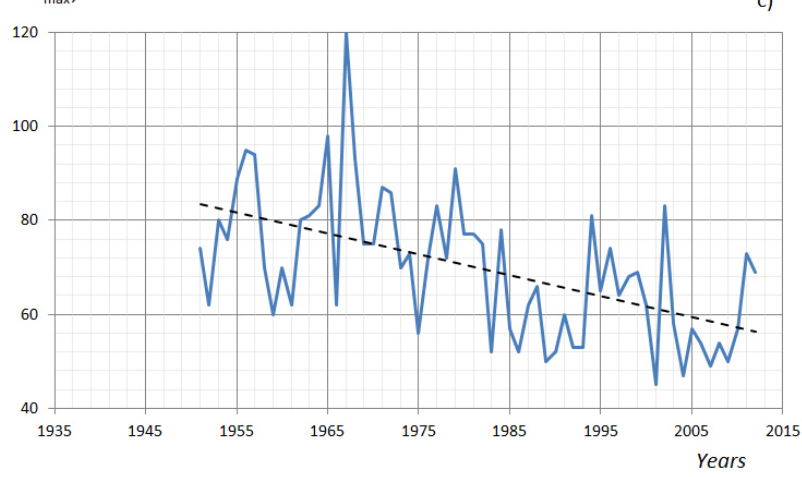

Figure 3. Changes in freeze-up date (a) and the duration of the freezing period (b), maximum of ice thickness on the Northern Dvina at Velikiy Ustyug (c) (dashed lines indicate linear trends).

steady temperature transition above $0{ }^{\circ} \mathrm{C}$. During last years this transition occurs earlier. According to the records of many weather stations, this tendency is statistically significant. Break-up dates during 1991-2013 occurred up to only 1-2 days earlier as compared to 1961-1990. The statistical analysis of break-up dates displayed lack of statistically significant trends.

The years of 2006 and 2007 showed examples of possible future ice regime changes. Despite ice appearance and freeze-up at the dates close to long-term mean ones, lengthy thawing spells in November and December 2006 contributed to ice cover destruction and break-up. The developed ice jams caused catastrophic increase of water level and flooding of developed territories in the Northern Dvina basin and created a risk of destruction of a motor road bridge at Kotlas city. Despite an early break-up in spring and low ice thickness, ice jams developed in the upstream area around Velikiy Ustyug town. Negative temperatures led to stabilization of the ice jam which lasted for 12 days despite of active measures to destroy it.

Measures to reduce water level rises caused by ice jams on the Northern Dvina were initiated since the 1950s. Works for ice weakening (ice blackening and cutting, as well as preventive explosive works on the most ice-jam-prone zones) are performed before break-ups. Ice jams were directly destroyed by explosions (including bombing) or weakened by preventive destruction of ice fields by icebreakers. However, the analysis of long-term fluctuations of the maximum levels induced by ice jams within the study reach over the recent decade does not show a significant positive effect of expensive ice-jam-control measures on the river rifts located downstream. Ice jams form on them almost every year and only in case of favorable climatic conditions (a relatively thin and weak ice cover, a low flood wave and slow snowmelt, and the passage of ice drifts on the Sukhona and Yug with a time lag), the spring flood on the Northern Dvina passes without significant damages.

\section{Materials, methods, and results}

Assessment of the flooded area is fulfilled by means of different hydrodynamic models (Pietroniro et al., 2001; Beltaos, 2003). The available observational data of 1896-2013 were used to calculate the maximum levels of the flow and ice jam origin and maximum water discharges of 1 and $5 \%$ recurrence at the boundaries of the reach under study. Twodimensional Saint-Venant equations were taken as a basis for a mathematical model of flooding. It has been developed by V. V. Belikov with colleagues since the 1990s. It is based on approaches of irregular hybrid computational meshes and original methods of interpolation (Belikov and Semenov, 2000). The system of Saint-Venant equations is most suitable for this class of problems, as it takes into account a real bed bathymetry and floodplain topography, thus allowing one to obtain the distribution of discharges over the branches of a braided riverbed and to evaluate flow velocities and depths at any point of the area. The simulation was performed using "STREAM-2D" software complex (Belikov et al., 2002). The two-dimensional equations were discretized on a triangular-quadrilateral mesh adapted to the channel network. The input data included the results of field studies with depth measurements; the slopes of water surface; measured water discharges and flow velocities, morphometric cross-sections through river valleys, the locations and elevations of road embankments, the presence of discharge openings; topographic maps with $1: 100000,1: 25000,1$ : 
50000 scales, data of long-term monitoring observations; satellite images over periods of spring flood and low water. The entire studied channel reach and the valley of the Northern Dvina from Velikiy Ustyug to Kotlas, including the mouth reaches of the Sukhona and Yug rivers, with a total length of about $90 \mathrm{~km}$, was studied to construct a hydrodynamic model. For model calibration, calculations were made for different scenarios related to the passage of maximum flow and ice jamming, including the data on the most catastrophic floods in 1998 and 2013. The difference between the calculated and measured water levels at all gauges within the reach never exceeded $30 \mathrm{~cm}$. In the case of ice jam formation, the model took into account the location and duration of ice jamming, the ice roughness factor in the ice jam reach, and the decrease in the average flow depth because of river bed filling with ice. The calculations showed that the existing model of water movement adequately reflects the real picture of flooding and can be used to assess the potential of possible flooding of the study area at different hydrological situations (Fig. 4). To assess the flood zones, situations (scenarios), at which the water levels of 1 and $5 \%$ recurrence, caused by ice jams, were simulated taking into account the possible construction of various protective structures. The simulation for each scenario (for current conditions and for the possible construction of bank protection dams) yielded the elevations of water surface, water depths, and flow velocities at each point of the two-dimensional model domain. The simulation showed that the water levels that formed by flood runoff of $1 \%$ recurrence may exceed the dry-season levels by $6-7 \mathrm{~m}$. In this case, more than $90 \%$ of the river valleys can be inundated. In the case of the ice jamming, the maximum levels may increase by another $2-3 \mathrm{~m}$.

In the calculations, the economic damage from the flooding of territories was divided into direct and indirect. The direct damage is associated with the direct physical contact of water with economic facilities, the amount of such damage being determined by the cost of restoration of the economy or the current market value of the destroyed (or damaged) economic facilities. The indirect economic losses are due to shutdown of facilities that process the production of plants, damaged by floods or inundations. The indirect damage also includes payments for shutdown periods, losses on transport, lost profits, adverse effects of flushed pollutants and damage to sewage treatment plants, manure storage structures, etc. The initial data for the assessment of damage to productive assets and finished products of companies, housing stock, and private property are data on the population in the flooded zone and elevations of the populated localities, as well as the type of residential and industrial buildings, which were classified according to the type of settlement. The lands subjected to flooding and waterlogging are defined in the riverside with the width corresponding to the rise of maximum levels of 1 and $5 \%$ recurrence. The method of assessing the economic damage caused by floods, which is used in the Russian practice, was adjusted according to the available statistical infor-

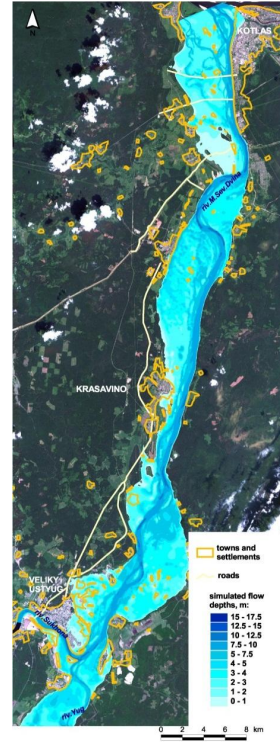

a)

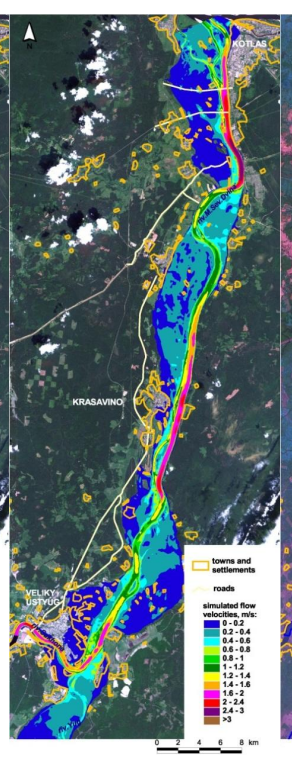

b)

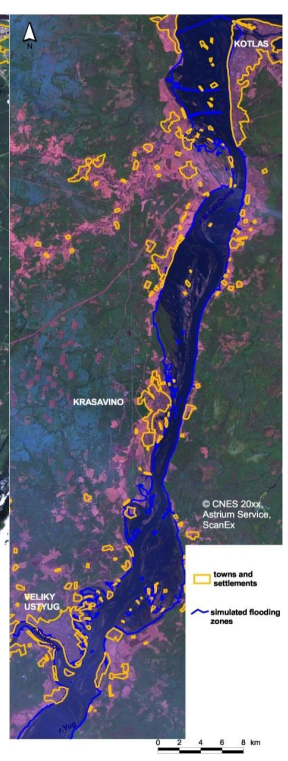

c)
Figure 4. The values of depths (a) and flow velocities (b) of the Northern Dvina at $1 \%$ recurrence calculated using "STREAM-2D" model and the comparison of floodplain boundaries obtained by modeling and taken from space photographs from Spot5 satellite on 5 May 2012 (c).

mation and economic and geographical characteristics of the territory (Shpagina et al., 2005). The calculations allowed estimating the total potential damage in the area of possible flooding. For example, in the case of a flood of $5 \%$ recurrence, it turned out that $70 \%$ of all costs are the costs of housing reconstruction and compensation to the population; $20 \%$ are the costs of the restoration of production facilities; $10 \%$ are the costs of rebuilding the social infrastructure. However, a comparison of the costs of eliminating the consequences of floods and the cost of construction of dams shows that the construction of flood control dams for the cities located on the banks of the Northern Dvina are effective only at a very high flood (1\% recurrence). The efficiency ratio (the ratio of the annual loss to the cost of protective structures) in this case is about $4-5$.

The above methods of prevention of adverse impacts of water are basic and based on the major hydrotechnical intervention in natural processes of water and streamflow regime. They also involve significant environmental risks. The measures aimed to reduce the ice jam component during the passage of the wave of a spring flood, are not as effective but more economical and "soft" for river ecosystems. In particular, the prevention of flooding of settlements is optimal when hydraulic engineering is combined with annual dredging. 


\section{Conclusions}

The analysis of current trends in the streamflow and hydrological regime of the Northern Dvina and the use of GIS technology and mathematical modeling of the flooding of floodplain-channel systems enabled formulating recommendations for preventing the inundation of populated localities and carrying out their critical evaluation. The results of model calculations provided a basis for recommendations and proposals for hydrotechnical engineering protection of populated localities by flood control dams and the assessment of their possible effectiveness and the ratio of the potential prevented damage to investments in the construction.

Acknowledgements. The study was supported by the Russian Science Foundation (Project no. 14-17-00700).

\section{References}

Belikov, V. V. and Semenov, A. Yu.: Non-Sibsonian interpolation on arbitrary system of points in Euclidean space and adaptive isolines generation, Appl. Numer. Math., 32, 371-387, 2000.

Belikov, V. V., Zaitsev, A. A., Militeev, A. H.: Mathematical modeling of complex reaches of large river channels, Water Resour., 29, 643-650, 2002.

Beltaos, S.: Numerical modelling of ice-jam flooding on the PeaceAthabasca delta, Hydrol. Process., 17, 3685-3702, 2003.

Frolova, N. L., Agafonova, S. A., Zavadski, A. S., and Krylenko, I. N.: Hazard assessment of hydrological phenomena at regional and local levels, Water Management Russia: problems, technology and management J., 3, 58-74, 2004 (in Russian).

Shpagina, A. H., Piterskaya, S. Y., and Fedorova, A. V.: Methods of assessment of the probability of damage from adverse effects of water and evaluation of the effectiveness of preventive measures of water management, FGUP (Federal State Unitary Enterprises) "VIAMS", M., 2005 (in Russian).

Pietroniro, A., Leconte, R., Peters, D. L., and Prowse, T. D.: Application of a hydrodynamic model in a freshwater delta using remote sensing, IAHS Publ. no. 267, 519-525, 2001.

Vuglinsky, V. S.: Peculiarities of ice events in Russian Arctic rivers, Hydrol. Process., 16, 905-913, 2002. 